\title{
Seismic technique to determine the allowable bearing pressure in soils and rocks
}

\author{
S. S. Tezcan ${ }^{1}$, Z. Ozdemir $^{1}$ \& A. Keceli ${ }^{2}$ \\ ${ }^{1}$ Bogazici University, Istanbul, Turkey \\ ${ }^{2}$ Istanbul University, Beyazit, Istanbul, Turkey
}

\begin{abstract}
Based on a variety of case histories of site investigations, including extensive bore hole data, laboratory testing and geophysical prospecting, an empirical formulation is proposed for the rapid determination of the allowable bearing capacity of shallow foundations. The proposed expression corroborates consistently with the results of the classical theory and is proven to be rapid, reliable and safe. It consists of only two soil parameters, namely the in situ measured shear wave velocity, and the unit weight. The unit weight may also be determined, with sufficient accuracy, by means of another empirical expression, using the P-wave velocity. It is indicated that once the shear and P-wave velocities are measured in situ by an appropriate geophysical survey, the allowable bearing pressure, as well as the coefficient of subgrade reaction and many other elasticity parameters, may be determined rapidly and reliably.

Keywords: bearing capacity, shear wave velocity, shallow foundations, allowable bearing pressure, seismic technique.
\end{abstract}

\section{Introduction}

Professor Schulze [1], a prominent historical figure in soil mechanics and foundation engineering in Germany, stated that "For the determination of allowable bearing pressure, the geophysical methods, utilising seismic wave velocity measuring techniques with absolutely no disturbance of natural site conditions, may yield relatively more realistic results than those of the geotechnical methods, which are based primarily on bore hole data and laboratory testing of so-called undisturbed soil samples". 
Since that time, various significant contributions have been made to solving geotechnical problems by means of geophysical prospecting. The P-wave velocities, for instance, have been used to determine the unconfined compressive strengths and modulus of elasticity of soil samples by Coates [2]. Hardin and Black [3], and also Hardin and Drnevich [4], based on extensive experimental data, established indispensable relations between the shear wave velocity, void ratio, and shear rigidity of soils. Similarly, Ohkubo and Terasaki [5] supplied various expressions relating the seismic wave velocities to weight density, permeability, water content, unconfined compressive strength and modulus of elasticity.

The use of geophysical methods in foundation engineering has been extensively studied also by Imai and Yoshimura [6], Tatham [7], Willkens et al. [8], Phillips et al. [9], Keçeli [10], Jongmans [11], Sully and Campanella [12], and Pyrak-Nolte et al. [13]. Campanella and Stewart [14] determined various soil parameters by digital signal processing, while Butcher and Powell [15] supplied practical geophysical techniques to assess various soil parameters related to ground stiffness. An empirical expression is also proposed by Abd El-Rahman et al. [16], for the ultimate bearing capacity of soils, using the logarithm of shear wave velocity. A series of guidelines have been also prepared in this respect by the Technical Committee TC 16 of IRTP, ISSMGE [17], and also by Sieffert and Bay-Gress [18]. Turker [19], and Tezcan et al. [21], based on extensive case studies, supplied explicit expressions for the allowable bearing pressure, using shear wave velocity. Massarsch [20] determined deformation properties of finegrained soils from seismic tests. Various geophysical techniques are available, as reported by Stokoe and Woods [22], Tezcan et al. [23], and Butcher et al. [24].

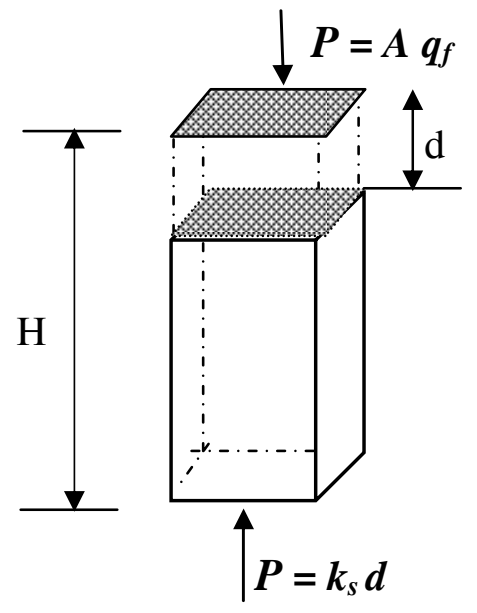

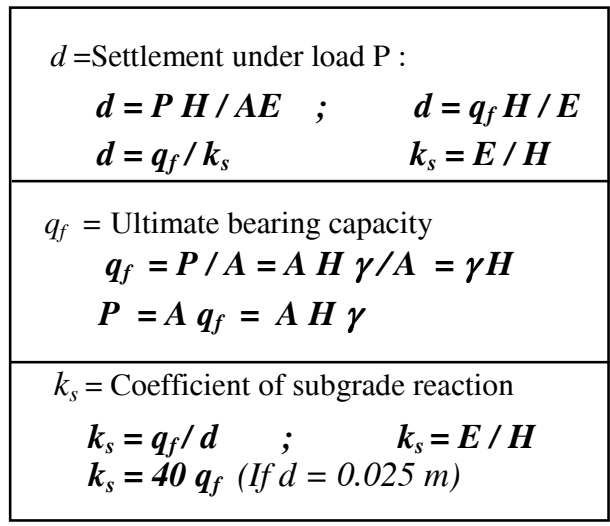

Figure 1: Soil column and related parameters. 


\section{Theoretical basis for the empirical expression}

The state of stress and the related elastic parameters of a soil column with a thickness $H$, is shown in Fig. 1. Assuming a unit cross-sectional area of $A=1$ the compressive stress at the base of the soil column becomes

$$
\begin{gathered}
\boldsymbol{q}_{f}=\gamma \boldsymbol{H} \\
\boldsymbol{q}_{\boldsymbol{a}}=\boldsymbol{q}_{\boldsymbol{f}} / \boldsymbol{n}=\gamma \boldsymbol{H} / \boldsymbol{n}
\end{gathered}
$$

where $q_{f}=$ ultimate bearing capacity at failure, $\gamma=$ unit weight of soil, $q_{a}=$ allowable bearing pressure, and $n=$ factor of safety. In order to be able to include the shear wave velocity $V_{s}$ into the above expressions of stresses the depth may be written as

$$
\boldsymbol{H}=\boldsymbol{V}_{\boldsymbol{s}} \boldsymbol{t}
$$

in which, $V_{s}=$ the shear wave velocity measured under the foundation within a depth $H, t=$ is an unknown time parameter. Substituting eqn (3) into eqn (2), yields

$$
\boldsymbol{q}_{a}=\gamma \boldsymbol{V}_{s} \boldsymbol{t} / \boldsymbol{n}
$$

The unknown time parameter, $t$, will now be determined on the basis of a calibration process. For this purpose, a typical 'hard' rock formation with the following parameters will be used

$$
\begin{array}{ccc}
q_{a}=10000 \mathrm{kN} / \mathrm{m}^{2}, & V_{s}=4000 \mathrm{~m} / \mathrm{sec} \\
\gamma= & 35 \mathrm{kN} / \mathrm{m}^{3}, \quad n=1.4
\end{array}
$$

Substituting these numerical values into eqn (4), we obtain $t=0.10 \mathrm{sec}$, thus;

$$
\boldsymbol{q}_{a}=0.1 \gamma \quad V_{s} / \boldsymbol{n}=\boldsymbol{q}_{f} / \boldsymbol{n} \text {, and } \boldsymbol{q}_{f}=0.1 \gamma \boldsymbol{V}_{s}
$$

This is the desired empirical expression to determine the allowable bearing pressure, $q_{a}$, in soils and rocks, once the unit weight, $\gamma$, and the in situ measured $V_{s}$ - wave velocities are available for the soil layer immediately beneath the foundation. The only unknown parameter is the factor of safety, $n$, which may be estimated as follows:

$$
\boldsymbol{n}=1.4\left(\text { for } V_{s} \geq 4000 \mathrm{~m} / \mathrm{sec}\right), \quad \boldsymbol{n}=4.0\left(\text { for } V_{s} \leq 750 \mathrm{~m} / \mathrm{sec}\right)
$$

For $V_{s}$ values $750<V_{s}<4000 \mathrm{~m} / \mathrm{sec}$ a linear interpolation is recommended. The factors of safety, as well as the empirical allowable bearing pressure expressions, for various soil (rock) types, are given in Table 1. It is determined by Terzaghi and Peck [25] that the width of footing, $B$, has a reducing influence on the value of allowable bearing pressure. Therefore, a correction factor $\beta$ is introduced into the formula, for 'soil' type formations only, as shown in the third line of Table 1. The proposed values of this correction factor, for different foundation width $B$, as deduced from Fig. 54.4 in [25], are as follows:

$$
\begin{array}{llr}
\beta=1.00 & \text { for } & (0 \leq B \leq 1.20 \mathrm{~m}) \\
\beta=1.13-0.11 B & \text { for } & (1.2 \leq B \leq 3.00 \mathrm{~m}) \\
\boldsymbol{\beta}=\mathbf{0 . 8 3 - 0 . 0 1 B} & \text { for } & (3.0 \leq B \leq 12.0 \mathrm{~m})
\end{array}
$$


Table 1: $\quad$ Factors of safety, n, for soils and rocks ${ }^{(1)}$.

\begin{tabular}{|l|l|l|l|}
\hline \multicolumn{1}{|c|}{ Soil type } & $\begin{array}{c}\mathrm{V}_{\mathrm{s}}-\text { range } \\
(\mathrm{m} / \mathrm{sec})\end{array}$ & \multicolumn{1}{|c|}{$\mathrm{n}$} & \multicolumn{1}{c|}{$\mathrm{q}_{\mathrm{a}}\left(\mathrm{kN} / \mathrm{m}^{2}\right)$} \\
\hline 'Hard' rocks & $\begin{array}{c}\mathrm{V}_{\mathrm{s}} \geq 4000 \\
750 \leq \mathrm{V}_{\mathrm{s}} \leq 4000 \\
750 \geq \mathrm{V}_{\mathrm{s}}\end{array}$ & $\begin{array}{l}\mathrm{n}=1.4 \\
\mathrm{n}=4.6-8.10^{-4} \mathrm{~V}_{\mathrm{s}} \\
\mathrm{n}=4.0\end{array}$ & $\begin{array}{l}\mathrm{q}_{\mathrm{a}}=0.071 \gamma \mathrm{V}_{\mathrm{s}} \\
\mathrm{q}_{\mathrm{a}}=0.1 \gamma \mathrm{V}_{\mathrm{s}} / \mathrm{n} \\
\mathrm{q}_{\mathrm{a}}=0.025 \gamma \mathrm{V}_{\mathrm{s}} \beta\end{array}$ \\
\hline 'Soft' rocks & &
\end{tabular}

${ }^{(1)}$ Linear interpolation is made for $750 \leq V_{s} \leq 4000 \mathrm{~m} / \mathrm{sec}$.

\section{Estimation of unit weight using $V_{p}$}

If the seismic $P$-wave velocity is measured, the unit weight, $\gamma$, may be determined, in $\mathrm{kN} / \mathrm{m}^{3}$ units, from anyone of the two following empirical expressions:

$$
\gamma=3.2 V_{p}^{0.25} \quad \text { or, } \quad \gamma=\gamma_{0}+0.002 V_{p}
$$

in which, $V_{p}=P$ - wave velocity in $m / s e c, \quad \gamma_{0}=$ the reference unit weight values in $\mathrm{kN} / \mathrm{m}^{3}$, for soil and rock types, given as follows:

$\gamma_{o}=16$ for loose sandy, silty and clayey soils,

$\gamma_{o}=17$ for dense sand and gravel,

$\gamma_{o}=18$ for mudstone, limestone, claystone, conglomerate, etc.,

$\gamma_{o}=20$ for cracked sandstone, tuff, graywacke, schist, etc.,

$\gamma_{o}=24$ for hard rocks.

The validity and reliability of these expressions, especially that of eqn (10), have been verified extensively, on the basis of numerous laboratory testing of real soil samples, as reported earlier by the writers [21]. The unit weights calculated by eqn (10) are in excellent agreement with those determined in the laboratory. In the absence of any borehole sampling and laboratory testing of soil samples, the above empirical expression provides a reliable first approximation for the unit weights of various soils, once the in-situ measured P-wave velocities are available. In fact, the speedy evaluation of unit weights, prior to any soil sampling, enables the practicing engineer to calculate the allowable bearing capacity $q_{a}$, readily from eqn (6a).

\section{Coefficient of subgrade reaction}

The shear wave velocity may be used successfully to determine $k_{s}=$ coefficient of subgrade reaction, and $E=$ modulus of elasticity, as already illustrated in Fig. 1. The coefficient of subgrade reaction, $k_{s}$, is defined, similar to the definition of spring constant in engineering mechanics, to be the necessary vertical pressure in order to produce a unit vertical displacement and expressed as; 


$$
\boldsymbol{k}_{s}=\boldsymbol{q}_{f} / \boldsymbol{d}
$$

For shallow foundations, the total vertical displacement is restricted to 1 inch $=0.025 \mathrm{~m}$, as prescribed by Terzaghi and Peck [25]. When, $d=0.025 \mathrm{~m}$ is substituted in eqn (11), the coefficient of subgrade reaction becomes in units of $k N / m^{3}$.

$$
\boldsymbol{k}_{s}=40 q_{f} \quad \text { or, } \quad \boldsymbol{k}_{s}=4 \gamma \boldsymbol{V}_{s}
$$

Similarly, the modulus of elasticity of the soil, $E$, under the foundation within a layer of thickness $H$, as shown in Fig. 1, is obtained from eqn (13)

$$
\boldsymbol{E}=\boldsymbol{k}_{s} \boldsymbol{H} \quad \text { or, } \quad \boldsymbol{E}=4 \gamma \boldsymbol{H} \boldsymbol{V}_{s}
$$

\section{Shear modulus- $G$, and Bulk modulus- $E_{k}$}

Once, $V_{p}$ and $V_{s}$ seismic wave velocities are measured, by geophysical means, for a particular sublayer in the field, several parameters of elasticity, such as, $G=$ Shear modulus, $E_{c}=$ Constraint modulus of elasticity, $E=$ Modulus of elasticity (Young's modulus), $E_{k}=$ Bulk modulus, and $\mu=$ Poisson's ratio may be obtained from the following expressions. The Shear modulus, $G$, and the Constraint modulus, $E_{c}$, are related to the shear and $P$ - wave velocities by the following expressions, respectively;

$$
\boldsymbol{G}=\rho \boldsymbol{V}_{s}^{2} \quad \text { and } \quad \boldsymbol{E}_{c}=\rho \boldsymbol{V}_{p}^{2}
$$

where $\rho=$ mass density given by $\rho=\gamma / g$. From, the Theory of Elasticity, it is known that, $E=$ the Young's modulus of elasticity is related to $E_{c}=$ the Constraint modulus and also to $G=$ the Shear modulus by the following expressions:

$$
\begin{aligned}
& E=E_{c}(1+\mu)(1-2 \mu) /(1-\mu) \\
& E=2(1+\mu) G
\end{aligned}
$$

Utilizing eqn (15) and substituting $\alpha$, as

$$
\alpha=E_{c} / G=\left(V_{p} / V_{s}\right)^{2}
$$

into eqn (16) and (17), we obtain

$$
2(1+\mu)=\alpha(1+\mu)(1-2 \mu) /(1-\mu)
$$

which yields, $\mu=$ Poisson's ratio, as

$$
\mu=(\alpha-2) / 2(\alpha-1) \quad \text { or, } \quad \alpha=(2 \mu-2) /(2 \mu-1)
$$

Similarly, the shear modulus, $G$, from eqn (15) is determined to be

$$
\boldsymbol{G}=\gamma \boldsymbol{V}_{s}^{2} / \boldsymbol{g}
$$

Hence, the modulus of elasticity $E$, is directly obtained from eqn (17), or, substituting eqn (20) into eqn (17), we obtain

$$
E=(3 \alpha-4) G /(\alpha-1)
$$


The Constraint modulus, $E_{c}$, may be also obtained in terms of $\alpha$ and $E$, from eqn (16) and eqn (18), as follows:

$$
E_{c}=\alpha E / 2(3 \alpha-4)
$$

The Bulk modulus, $E_{k}$, of the soil layer, may be expressed, from the theory of elasticity, as

$$
\begin{gathered}
E_{k}=E / 3(1-2 \mu) \\
E_{k}=(\alpha-1) E / 3=\gamma\left(V_{p}^{2}-4 V_{s}^{2} / 3\right) / g
\end{gathered}
$$

For purposes of quick and convenient reference, various elasticity parameters of the soil or rock layer immediately under a shallow foundation, for which the

\begin{tabular}{|c|c|c|c|}
\hline Symbol & Title & Formula & Equation \\
\hline $\boldsymbol{G}$ & $\begin{array}{l}\text { Shear } \\
\text { modulus }\end{array}$ & $\mathrm{G}=\gamma \mathrm{V}_{\mathrm{S} \cdot \mathrm{g}}^{2 \tau}$ & eqn (21) \\
\hline $\boldsymbol{E}$ & $\begin{array}{l}\text { Modulus of } \\
\text { elasticity }\end{array}$ & $\begin{array}{l}\mathrm{E}=\mathrm{k}_{\mathrm{s}} \mathrm{H}=4 \gamma \mathrm{H} \mathrm{V}_{\mathrm{s}} \quad \text { (Alternate) } \\
\mathrm{E}=(3 \alpha-4 \mathrm{G} /(\alpha-1)=2(1+\mu) \mathrm{G}\end{array}$ & $\begin{array}{l}\text { eqn (14) } \\
\text { eqn (22) }\end{array}$ \\
\hline $\boldsymbol{E}_{c}$ & $\begin{array}{l}\text { Constraint } \\
\text { modulus }\end{array}$ & $\begin{array}{l}\mathrm{E}_{\mathrm{c}}=(1-\mu) \mathrm{E} /(1+\mu)(1-2 \mu) \\
\mathrm{E}_{\mathrm{c}}=\alpha \mathrm{E} / 2(3 \alpha-4)\end{array}$ & $\begin{array}{l}\text { eqn (16) } \\
\text { eqn (23) }\end{array}$ \\
\hline$E_{k}$ & $\begin{array}{l}\text { Bulk } \\
\text { modulus }\end{array}$ & $\begin{aligned} \mathrm{E}_{\mathrm{k}}= & \mathrm{E} / 3(1-2 \mu)= \\
& 2(1+\mu) \mathrm{G} / 3(1-2 \mu) \\
\mathrm{E}_{\mathrm{k}}= & (\alpha-1) \mathrm{E} / 3=\gamma\left(\mathrm{V}_{\mathrm{p}}^{2}-4 \mathrm{v}_{\mathrm{s}}^{2} / 3\right) / \mathrm{g}\end{aligned}$ & $\begin{array}{l}\text { eqn }(24) \\
\text { eqn }(25)\end{array}$ \\
\hline$\mu$ & $\begin{array}{l}\text { Poisson's } \\
\text { ratio }\end{array}$ & $\begin{array}{l}\mu=(\alpha-2) / 2(\alpha-1) \\
\alpha=2(\mu-1) /(2 \mu-1)\end{array}$ & $\begin{array}{l}\text { eqn }(20 a) \\
\text { eqn }(20 b)\end{array}$ \\
\hline $\boldsymbol{k}_{\mathrm{s}}$ & $\begin{array}{l}\text { Subgrade } \\
\text { coefficient }\end{array}$ & $\mathrm{k}_{\mathrm{s}}=4 \gamma \quad \mathrm{V}_{\mathrm{s}}=40 \mathrm{q}_{\mathrm{f}}$ & eqn (13) \\
\hline$q_{a}$ & $\begin{array}{l}\text { Allowable } \\
\text { bearing } \\
\text { pressure }\end{array}$ & $\mathrm{q}_{\mathrm{a}}=\mathrm{q}_{\mathrm{f}} / \mathrm{n}=0.1 \gamma \mathrm{V}_{\mathrm{s}} \beta / \mathrm{n}$ & eqn $(6)$ \\
\hline
\end{tabular}
$V_{p}$ and $V_{s}$ - wave velocities are available, are summarized in Table 2.

Table 2: $\quad$ Various elasticity parameters in terms of $V_{p}$ and $V_{s}$

$\alpha=\mathrm{E}_{\mathrm{c}} / \mathrm{G}=\left(\mathrm{V}_{\mathrm{p}} / \mathrm{V}_{\mathrm{s}}\right)^{2}$

$\beta=$ Correction factor for the width of foundation (see Eq.(8), only in soils, not in rocks. 


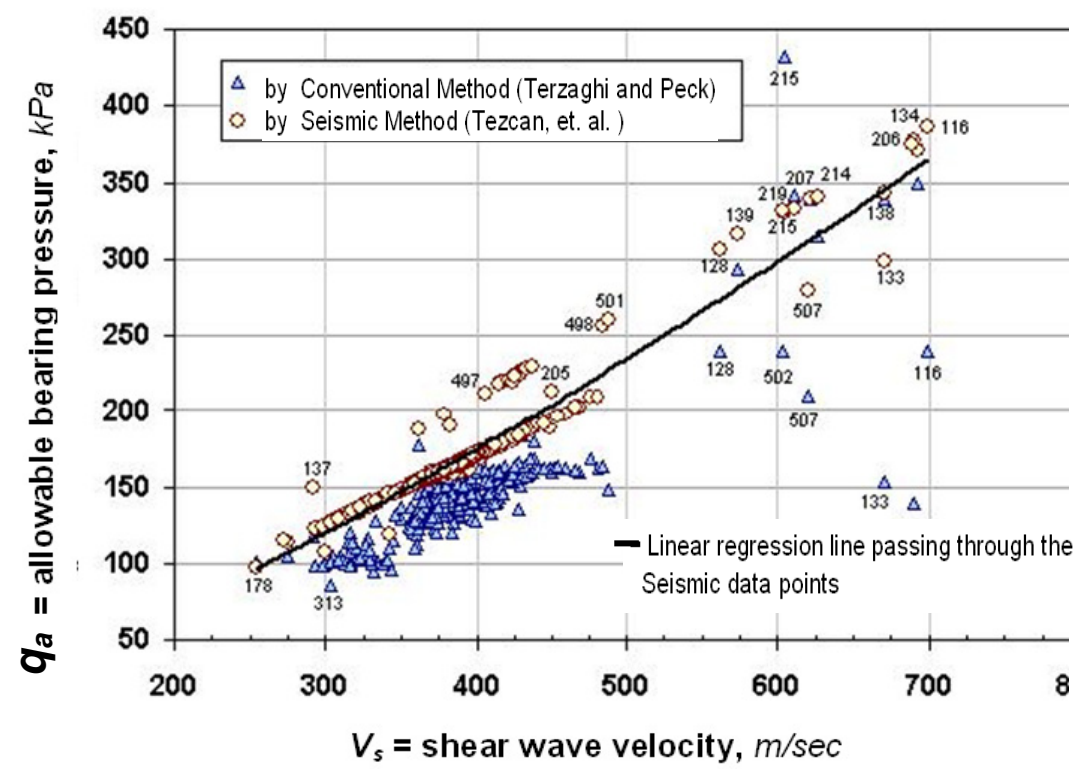

Figure 2: $\quad$ Comparison of conventional and seismic methods.

\section{Numerical example}

For purposes of illustration, a soft clayey soil layer of $H=15 \mathrm{~m}$ beneath a shallow foundation will be considered. The in situ measured seismic wave velocities are determined to be $V_{p}=700 \mathrm{~m} / \mathrm{sec}$ and $V_{s}=200 \mathrm{~m} / \mathrm{sec}$. A comprehensive set of classical soil investigations, including a number of bore hole data and laboratory testing exist for this particular site, together with the numerical values of various soil parameters, including the allowable bearing pressure determined by the classical method of Tezgahi and Peck [25]. Therefore, the validity and the reliability of the proposed empirical formulae have been rigorously verified. Calculation of the same soil parameters, using the empirical expressions presented herein, are summarized in Table 3. The numerical results of the empirical method are in very close agreement with those of the geotechnical survey.

\section{Case studies}

The allowable bearing pressures have been determined at more than 373 construction sites in and around the Kocaeli and Istanbul Provinces in Turkey, between the years 2005-08. At each construction site, by virtue of City by-law, a sufficient number of bore holes were drilled, SPT counts conducted, undisturbed soil samples were taken for laboratory testing purposes, where shear strength, $c$, 
Table 3: Results of numerical example $\left(H=15 \mathrm{~m}, \mathrm{~V}_{\mathrm{p}}=700 \mathrm{~m} / \mathrm{sec}, \mathrm{V}_{\mathrm{s}}=200\right.$ $\mathrm{m} / \mathrm{sec})$.

\begin{tabular}{|c|c|c|c|c|}
\hline Formula & Equation & $\begin{array}{l}\text { Numerical } \\
\text { calculations }\end{array}$ & Result & Unit \\
\hline $\begin{array}{l}\gamma=3.2 \mathrm{~V}_{\mathrm{p}}^{0.25} \\
\gamma=\gamma_{0}+0.002 \mathrm{~V}_{\mathrm{p}}\end{array}$ & $\begin{array}{l}\text { eqn (9) } \\
\text { eqn (10) }\end{array}$ & $\begin{array}{c}\gamma=3.2(700)^{0.25} \\
\gamma=16+0.002(700)\end{array}$ & $\begin{array}{c}16.5 \\
17.4^{(1)}\end{array}$ & $\begin{array}{l}\mathrm{kN} / \mathrm{m}^{3} \\
\mathrm{kN} / \mathrm{m}^{3}\end{array}$ \\
\hline $\mathrm{n}=4$ & Table 1 & $\mathrm{~V}_{\mathrm{s}} \leq 700 \mathrm{~m} / \mathrm{sec}$ & 4 & - \\
\hline $\mathrm{q}_{\mathrm{f}}=0.1 \gamma \mathrm{V}_{\mathrm{s}}$ & eqn $(6 b)$ & $\mathrm{q}_{\mathrm{f}}=0.1(17.4) 200$ & 348 & $\mathrm{kN} / \mathrm{m}^{2}$ \\
\hline $\mathrm{q}_{\mathrm{a}}=\mathrm{q}_{\mathrm{f}} / \mathrm{n}$ & eqn $(6 a)$ & $\mathrm{q}_{\mathrm{a}}=348 / 4$ & 87 & $\mathrm{kN} / \mathrm{m}^{2}$ \\
\hline $\mathrm{k}_{\mathrm{s}}=40 \mathrm{q}_{\mathrm{f}}$ & eqn (12) & $\mathrm{k}_{\mathrm{s}}=40(348)$ & 13920 & $\mathrm{kN} / \mathrm{m}^{3}$ \\
\hline $\mathrm{E}=\mathrm{k}_{\mathrm{s}} \mathrm{H}$ & eqn (14) & $\mathrm{E}=13920(15)$ & 208800 & $\mathrm{kN} / \mathrm{m}^{2}$ \\
\hline $\mathrm{G}=\gamma \mathrm{V}_{\mathrm{s}}^{2} / \mathrm{g}$ & eqn (21) & $\mathrm{G}=17.4(200)^{2} / 9.81$ & 70948 & $\mathrm{kN} / \mathrm{m}^{2}$ \\
\hline$\alpha=\left(V_{p} / V_{s}\right)^{2}$ & eqn (18) & $\alpha=(700 / 200)^{2}$ & 12.25 & - \\
\hline $\begin{array}{l}\mu=(\alpha-2) / 2(\alpha- \\
1)\end{array}$ & eqn (20) & $\mu=(12.25-2) / 2(11.25)$ & 0.456 & - \\
\hline $\mathrm{E}=2(1+\mu) \mathrm{G}$ & eqn (17) & $\mathrm{E}=2(1.456) 70948$ & 206537 & $\mathrm{kN} / \mathrm{m}^{2}$ \\
\hline $\begin{array}{l}E_{c}=\alpha E / 2(3 \alpha- \\
4)\end{array}$ & eqn (23) & $206537(12.25) / 2(32.75)$ & 38627 & $\mathrm{kN} / \mathrm{m}^{2}$ \\
\hline $\mathrm{E}_{\mathrm{k}}=\mathrm{E} / 3(1-2 \mu)$ & eqn (24) & 206537 / $3(1-0.91)$ & 774510 & $\mathrm{kN} / \mathrm{m}^{2}$ \\
\hline$E_{k}=E(\alpha-1) / 3$ & eqn (11) & $206537(12.25-1) / 3$ & 774510 & $\mathrm{kN} / \mathrm{m}^{2}$ \\
\hline $\mathrm{d}=$ displacement & eqn (11) & $\mathrm{d}=0.025 \mathrm{~m}$ & 0.025 & $\mathrm{~m}$ \\
\hline
\end{tabular}

${ }^{(1)}$ Result of eqn (10), $\gamma=17.4 \mathrm{kN} / \mathrm{m}^{3}$ is used in all subsequent expressions.

and internal angle of friction $\phi$ were determined. Subsequently, following the classical procedure of Terzaghi and Peck [25], the ultimate and also the allowable bearing pressures were determined, by assuming the factor of safety as $n=3$. For granular soils, immediate settlement calculations were also conducted, in order to determine whether the shear failure mechanism or the maximum settlement criterion would control the design. The numerical values of the 
allowable bearing pressures, $q_{a}$, determined in accordance with the conventional Terzaghi theory, are shown by a triangular $(\Delta)$ symbol, in Fig. 2 .

Parallel to these classical soil investigations, the $P$ - and $S$ - wave velocities have been measured in situ, right at the foundation level for the purpose of determining the allowable bearing pressures, $q_{a}$, which are shown by means of a circle (o), in Fig. 2.

A solid linear regression line was also shown in Fig. 2, for the purpose of indicating the consistency, uniformity, and stability of the allowable bearing pressures, $q_{a}$, determined by the seismic method proposed herein. The list of soil parameters determined by in situ and laboratory testing through geotechnical prospecting, as well as the in situ measured $V_{p}$ and $V_{s}$-velocities at each site, are too voluminous to be included herein. Those researchers interested in having access to this particular database may contact the author via email at tezokan@gmail.com.

\section{Conclusions}

- The shear wave velocity is a single and most powerful soil parameter representing a family of geotechnical soil parameters, ranging from compressive strength to void ratio, from shear rigidity to cohesion etc,

- Extensive bore hole and laboratory testing of soil samples would no longer be needed if the shear and P-wave velocities are measured, as accurately as possible, right under the foundation level. Then, the allowable bearing pressure, the coefficient of subgrade reaction, various other elasticity parameters, as well as the approximate value of the unit weight are rapidly determined, using relatively simple empirical expressions.

\section{References}

[1] Schulze, W.E., "Grundbau”, Deutsche Forschungsgesellschaft für Bodenmechanik, $7^{\text {th }}$ ed., B.G. Taubner Publishers, Leipzig, Germany. Also available: Technical University of Istanbul, Issue 48, No DK624-15, Uçler Printing House, Istanbul, Turkey, 1943.

[2] Coates, D.F., Rock Mechanics Principles: Mines Branch Monographs, No. $874,1970$.

[3] Hardin, B. O., and Black, W.L., Vibration modulus of normally consolidated clays, Journal of the Soil Mechanics and Foundation Division, ASCE, Vol.94, No. SM2, pp.353-369, 1968.

[4] Hardin, B.O., and Drnevich, V.P., Shear modulus and damping in soils. Journal of the Soil Mechanics and Foundation Division ASCE, Vol. 98, No. SM7, pp.667-692, 1972.

[5] Ohkubo, T., and Terasaki, A., Physical property and seismic wave velocity of Rocks. OYO Corporation, Japan, 1976.

[6] Imai, T., and Yoshimura, M., The relation of mechanical properties of soils to $\mathrm{P}$ and S- Wave velocities for soil ground in Japan. Urana Research Institute, OYO Corporation, 1976. 
[7] Tatham, R.H., $\mathrm{V}_{\mathrm{p}} / \mathrm{V}_{\mathrm{s}}$ and lithology. Geophysics, 47:336-344, 1982.

[8] Willkens, R., Simmons G. \& Caruso, L., The Ration $V_{p} / V_{s}$ as a discriminant of composition for siliceous limestones. Geophysics, 49(11) 1850-1860, 1984.

[9] Phillips, D. E., Han, D. H. \& Zoback, M. D., Empirical relationships among seismic velocity, effective pressure, porosity, and clay content in sandstone. Geophysics, 54:(1) 82-89, 1989.

[10] Keçeli, A. D., Determination of bearing capacity of soils by means of seismic methods (in Turkish), Geophysical Journal, Ankara, Turkey, 4, 8392, 1990.

[11] Jongmans, D., The application of seismic methods for dynamic characterization of soils. Bulletin of International Association of Engineering Geology. 46:63-69, 1992.

[12] Sully, J. P. \& Campanella, R.G., Evaluation of in situ anisotropy from crosshole and downhole shear wave velocities measurements. Geotechnique, 45(2):267-282, 1995.

[13] Pyrak-Nolte, L. J., Roy, S. \& Mullenbach, B., 1., Interface waves propagated along a fracture. Journal of Applied Geophysics, 35:79-87, 1996.

[14] Campanella, R.G. and Stewart, W.P. "Seismic cone analysis using digital signal processing for dynamic site characterization", Canadian Geotechnical Journal, Vol.29, No.3, June 1992, pp.477-486, 1992.

[15] Butcher, A.P. and Powell, J.J., Practical considerations for field geophysical techniques to used assess ground stiffness. Proc. Int. Conf. on Advances in Site Investigation Practice, ICE London, March 1995. Thomas Telford, pp 701-714, 1995.

[16] Abd El-Rahman, M.M, Setto, I., and El-Werr, A., Inferring mechanical properties of the foundation material, from geophysical measurements. Egyptian Geophysical Society, Proceedings of the $9^{\text {th }}$ Annual Meeting, pp. 206-228, 1992.

[17] IRTP, ISSMGE Technical Committee TC16 Ground Property Characterization from In-situ Testing, International Reference Test Procedure (IRTP) for the Cone Penetration Test (CPT) and the Cone Penetration Test with pore pressure (CPTU). Proc. XIIth ECSMGE Amsterdam. Balkema. pp 2195-2222, 1999.

[18] Sieffert, J. G., and Bay-Gress, Ch, Comparison of the European bearing capacity calculation methods for shallow foundations. Geotechnical Engineering, Institution of Civil Engineers, Vol. 143, pp. 65-74, England, 2000.

[19] Turker, E., Computation of ground bearing capacity from shear wave velocity, Continuum Models and Discrete Systems, Eds. D. Bergman, et al., Netherlands, pp. 173-180, 2004.

[20] Massarsch, K. R. Deformation properties of fine-grained soils from seismic tests. Keynote lecture, International Conference on Site Characterization, ISC'2, 19-22 Sept. 2004, Porto, 133-146, 2004. 
[21] Tezcan, S. S., Ozdemir, Z., and Keceli, A., Allowable bearing capacity of shallow foundations based on shear wave velocity, Journal of Geotechnical and Geological Engineering, 24: pp. 203-218, DOI 10.1007 / s.10706-0041748-4, Netherlands, Springer, www.springerlink.com, 2006.

[22] Stokoe, K. H., and Woods, R.D., In situ shear wave velocity by cross-hole method, Journal of the Soil Mechanics and Foundation Division, ASCE, Vol. 98, No.SM5, pp.443-460, 1972.

[23] Tezcan, S. S., Erden, S. M., and Durgunoğlu, H. T., Insitu measurement of shear wave velocity at Boğaziçi University Campus, Proc. of the International Conference on Soil Mechanics and Foundation Engineering, Vol. 2, April 1975, pp. 157-164, Istanbul Technical University, Istanbul, Turkey, 1975.

[24] Butcher, A.P., Campanella, R.G., Kaynia, A.M., and Massarsch, K. R., Seismic cone downhole procedure to measure shear wave velocity - A guideline prepared by ISSMGE TC10: Geophysical Testing in Geotechnical Engineering. Proc. of the XVIth International Conference on Soil Mechanics and Geotechnical Engineering May 2006, 5p, Osaka, Japan.

[25] Terzaghi, K., and Peck, R.B., Soil Mechanics in Engineering Practice. $2^{\text {nd }}$ ed., John Wiley \& Sons, London, 1976. 